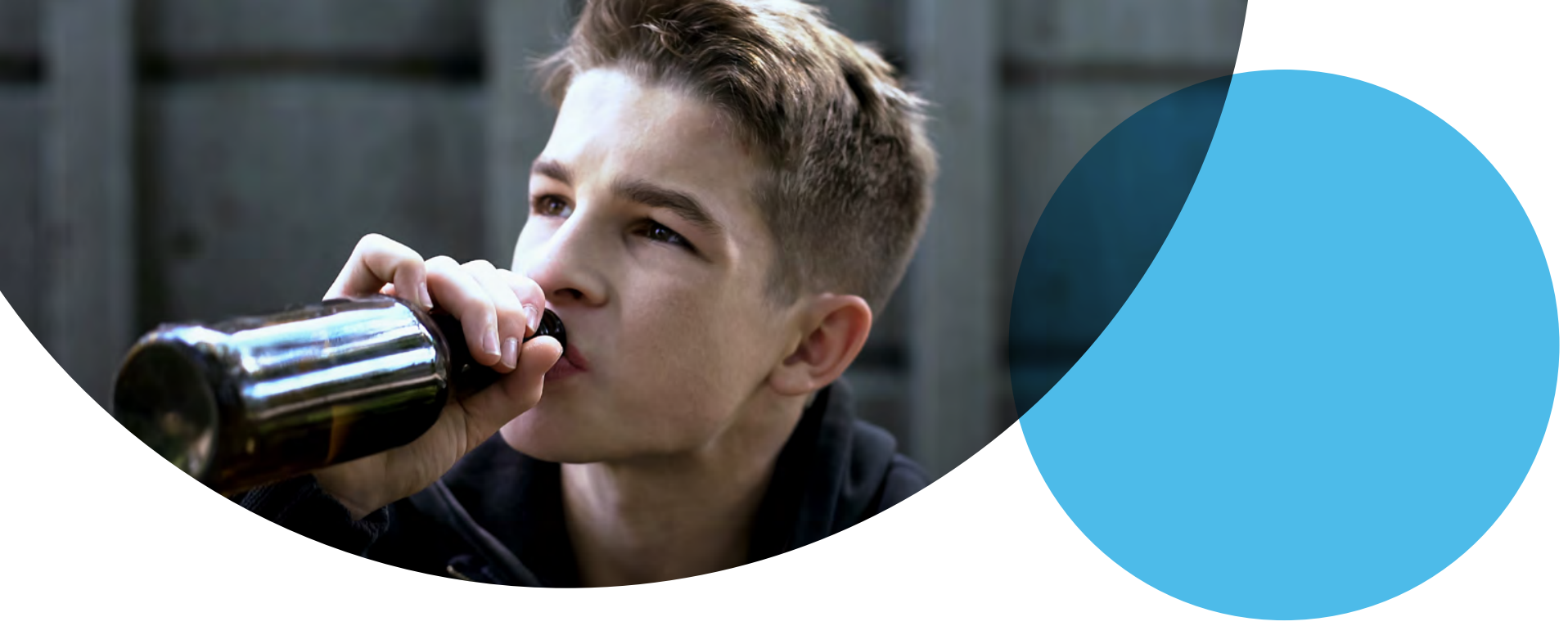

\title{
Presenting as 'in control' may mask risk for alcohol misuse in adolescents with symptoms of BPD
}

\section{By Dr. Jessica K Edwards}

An association between borderline personality disorder (BPD) and alcohol and/or drug misuse is widely acknowledged in adults. ${ }^{1}$ However, not much data exists to explain the factors underlying such an association in adolescents. This year, Johanna Folk and colleagues at George Mason University, USA, published their findings from a sample of 181 psychiatrically hospitalized adolescents who completed various self-assessments on their alcohol use and perceived coping skills. They found that adolescents who used alcohol to self-medicate were at high risk of alcohol problems in later life, regardless of BPD symptoms. Paradoxically, those with higher perceived levels of coping skills were at the highest risk: these individuals tended to drink more and have more alcohol problems.

"Adolescents who experience symptoms of BPD often exhibit a phenomenon called apparent competence - i.e. they present as being 'in control', but are actually experiencing extreme distress and lack sufficient coping skills", explains Folk. "For this reason, and in light of our data, we encourage clinicians to collect collateral reports of adolescent's coping abilities rather than relying solely on self-report".

The researchers also propose that clinicians should not only assess if adolescents are using alcohol, but also determine why they are doing so. "Clinicians should focus on teaching alternative coping strategies when self-medication and/or rebellion are identified as reasons for drinking", said Folk, "as these seem to be associated with greater alcohol misuse".

\section{Referring to:}

Folk, J.B., Williams, C.A. \& EspositoSmythers, C. (2020), Alcohol misuse among adolescents with $B P D$ symptoms: exploring the moderating role of reasons for drinking and perceived coping skills in a clinical adolescent sample. Child Adolesc. Ment. Health. doi: 10.111/camh.12378.

\section{References:}

${ }^{1}$ Trull. T.J., et al. (2018). Borderline personality disorder and substance use disorders: an updated review. Borderline Personal. Disord. Emot. Dysregul. 5:15. doi: 10.1186/s40479018-0093-9.

\section{Glossary:}

\section{Borderline personality disorder:}

According to the DSM-5, "bipolar personality disorder is diagnosed on the basis of (1) a pervasive pattern of instability of interpersonal relationships, selfimage, and affects, and (2) marked impulsivity beginning by early adulthood and present in a variety of contexts". 